Check for updates

Cite this: Chem. Sci., 2019, 10, 4192

๑ All publication charges for this article have been paid for by the Royal Society of Chemistry

Received 12th January 2019

Accepted 5th March 2019

DOI: $10.1039 / c 9 s c 00190$ e

rsc.li/chemical-science

\title{
Construction of a cross-layer linked G-octamer via conformational control: a stable G-quadruplex in $\mathrm{H}$-bond competitive solvents $\dagger$
}

\author{
Ying He,,$^{\mathrm{a}}$ Yanbin Zhang, $\dot{+}^{\mathrm{b}}$ Lukasz Wojtas, ${ }^{\mathrm{a}}$ Novruz G. Akhmedov, ${ }^{\mathrm{c}}$ David Thai, ${ }^{a}$ \\ Heng Wang, ${ }^{a}$ Xiaopeng Li, ${ }^{a}$ Hao Guo (D) ${ }^{* b}$ and Xiaodong Shi (DD *a
}

\begin{abstract}
Methanol soluble and stable guanosine octamers were successfully achieved via $\mathrm{H}$-bond self-assembly. Through structural conformational design, we developed a new class of guanosine derivatives with modification on guanine $\left(8\right.$-aryl) and ribose $\left(2^{\prime}, 3^{\prime}\right.$-isopropylidene). This unique design led to the formation of the first discrete $G_{8}$-octamer with its structure characterized by single crystal $X$-ray diffraction, MS and NMR spectroscopy. The $G_{8}$-octamer showed unique cation recognition properties, including the formation of a stable $\mathrm{Rb}^{+}$templated G-quadruplex. Based on this observation, further modification on the 8-aryl moiety was performed to incorporate a cross-layer $\mathrm{H}$-bond or covalent linkage. Similar G-octamers were obtained in both cases with structures confirmed by single crystal $\mathrm{X}$-ray diffraction. Furthermore, the covalently linked G-quadruplex exhibited excellent stability even in $\mathrm{MeOH}$ and DMSO, suggesting a promising future for this new $\mathrm{H}$-bond self-assembly system in biological and material applications.
\end{abstract}

\section{Introduction}

Non-covalent interactions enable construction of large structural motifs from small molecules. ${ }^{1-3}$ Molecular self-assembly, an important process typically driven by non-covalent interactions, is often dynamic and generally under thermodynamic control. ${ }^{4,5}$ With interest in the application of the self-assembly process to biomedical research, there is a growing demand with respect to preparing stable non-covalent assemblies in a biocompatible environment. ${ }^{6-8}$ However, supramolecular structures built through $\mathrm{H}$-bonds are often studied in less polar aprotic solvents (such as $\mathrm{CH}_{2} \mathrm{Cl}_{2}$ ) to avoid the competition of $\mathrm{H}$ bond interactions between substrates and solvents. ${ }^{\mathbf{9} 10}$ Thus, the development of novel supramolecular systems which are stable in a polar protic solvent is highly desirable, though very challenging. ${ }^{11,12}$

A G-quartet is an interesting supramolecular scaffold formed by H-bonds. ${ }^{13,14}$ As shown in Scheme 1, with an approximately 90-degree angle between the $\mathrm{H}$-bond donor and acceptor, four

${ }^{a}$ Department of Chemistry, University of South Florida, 4202 E. Fowler Avenue, Tampa, Florida 33620,USA. E-mail: xmshi@usf.edu

${ }^{b}$ Department of Chemistry, Fudan University, 2005 Songhu Road, Shanghai, 200438, People's Republic of China

'Department of Chemistry, West Virginia University, Morgantown, WV 26505, USA

$\dagger$ Electronic supplementary information (ESI) available: Experimental section, NMR spectra, ESI-MS spectra and crystallographic data. CCDC 1871565-1871570 and 1871754. For ESI and crystallographic data in CIF or other electronic format see DOI: 10.1039/c9sc00190e

\$ Equal contribution. guanine units are held together to form a G-quartet. Through ion-dipole interactions, alkali and alkaline earth metal cations can enhance the process by serving as the template to coordinate with central oxygen atoms. ${ }^{15-17}$ Stacking of G-quartets gives G-quadruplexes as bioactive building blocks found in DNA and RNA folding: ${ }^{18,19}$ In this case, the extent of G-quartet stacking in a G-quadruplex will be determined by the phosphate backbone, which is often associated with the formation of a counter folding subunit, such as the i-motif. ${ }^{20}$

Inspired by this unique $\mathrm{H}$-bond assembly, researchers have been devoted to developing guanine derivatives to achieve controllable G-quadruplex formation from small molecules. ${ }^{21-23}$ Some interesting applications have been identified with various G-quartet assemblies, including lipophilic ion channels, ${ }^{\mathbf{2 4 - 2 6}}$ supramolecular hydrogels, ${ }^{27-29}$ nanomaterials, ${ }^{30,31}$ potential targets for cancer therapy,,$^{32,33}$ and more. ${ }^{34-37}$ Although many examples of G-quartet formation through various modified

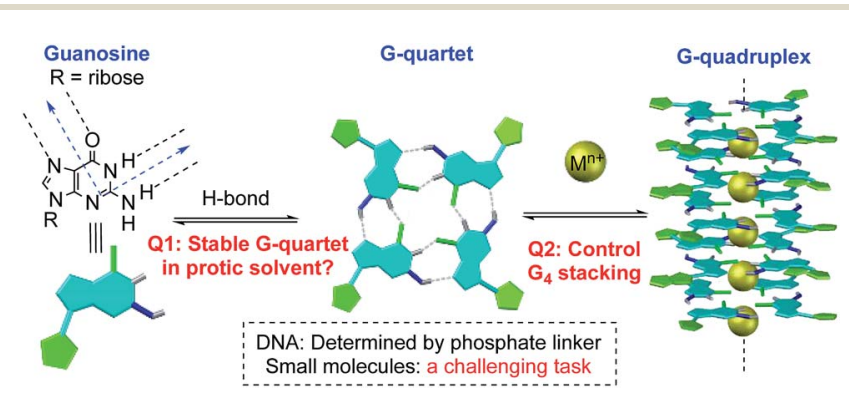

Scheme 1 G-quadruplex formation: equilibrium and stability. 
guanine derivatives have been reported, studies on controlling G-quartet stacking molecularity are relatively rare.$^{38,39}$ Factors to be taken into consideration include the cation concentration, ${ }^{39}$ the solvent, ${ }^{40}$ the anion, ${ }^{41}$ and so on. ${ }^{42}$ In many cases, mixtures of various "stacking isomers" $\left(\mathrm{G}_{8}, \mathrm{G}_{12}\right.$ or $\left.\mathrm{G}_{16}\right)$ were observed, which highlights the significant challenges associated with controlling the vertical stacking. ${ }^{43-46}$ Moreover, the assembly of a specific and stable G-quadruplex in H-bond competitive solvents remains a challenging task. ${ }^{48}$ Herein, we report the construction of the first G-octamer with structures characterized by single crystal X-ray diffraction through monomer conformational design. Moreover, with this new system, stable G-quadruplexes were formed with significantly improved stability. Through the design of cross-layer $\mathrm{H}$-bonds and covalent linkage, G-octamers were prepared with excellent stability in $\mathrm{MeOH}$ (no dissociation) and even in 50\% DMSO, which offers a potential opportunity to extend the $\mathrm{H}$-bond assembly system into biosystems for future applications.

\section{Results and discussion}

\section{Design, synthesis and characterization of G-octamers}

Ideally, $\mathrm{a} \mathrm{G}_{4}$-tetramer would be the most concise target towards the construction of a simple and stable assembled structure. However, with a metal template in solution, further stacking of $\mathrm{G}_{4}$-tetramers leads to the mixture of G-quadruplex species. ${ }^{49}$ Thus, $\mathrm{G}_{4}$-tetramers are unfavorable for the formation of welldefined supermolecules.

The simplest plausible G-quadruplex would be a G-octamer which is likely to adopt either top-to-top (T-T) or bottom-tobottom (B-B) stacking patterns (Scheme $2 \mathrm{~A}$ ). ${ }^{50}$ In previous

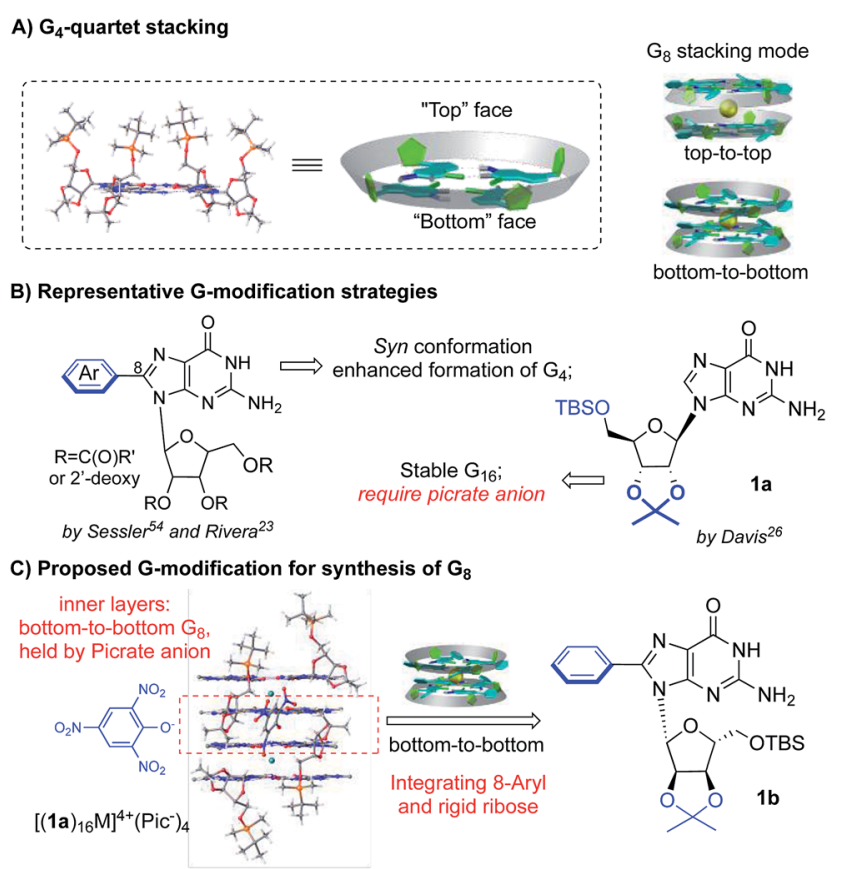

Scheme 2 Achieving a stable G-octamer by controlling G-quartet stacking. studies, Meijer et al. employed different concentrations of a guanosine derivative resulting in the formation of tunable Goctamers. ${ }^{41}$ Spada has reported G-octamer formation upon exposure to UV light through alkene isomerization..$^{51} \mathrm{Wu}$ presented several excellent examples of G-octamer formation through $\pi-\pi$ interactions using NMR and MS studies..$^{52}$ Hirao and coworkers applied $\mathrm{Au}(\mathrm{I})-\mathrm{Au}(\mathrm{I})$ interaction between two Gquartet layers to achieve a G-octamer confirmed by NMR and CD spectra..$^{53}$ However, to the best of our knowledge, no single crystal structure of a G-octamer has ever been reported, implying the challenging nature of preparing a stable and discrete G-octamer in a dynamic equilibrium.

To tackle this problem, we set out to design a G-derivative where the structure is rigid and predisposed for the conformation of a potential octamer structure so as to minimize the entropy cost involved in the self-assembly process. As shown in Scheme 2B, modification of guanosine often occurs on two positions: C-8 of purine and the hydroxyl of ribose. The Sessler group first reported on 8-aryl substituted guanosine in the formation of a G-quartet without templating cation in both solution and solid state. ${ }^{54}$

This seminal work initiated the concept of conformational control for G-quartet formation: the steric effect between the aryl substituent and protected ribose helped guanosine to adopt a syn conformation, preventing the ribbon formation and giving a tetramer as the dominant conformation. On the other hand, Davis's group developed lipophilic guanosine with bulky ribose to form a G-hexadecamer (Scheme 2B) both in solution and solid state $\left(\mathrm{M}^{\mathrm{n}+}=\mathrm{K}^{+}, \mathrm{Ba}^{2+}, \mathrm{Sr}^{2+}\right.$, and $\left.\mathrm{Pb}^{2+}\right) .{ }^{55}$ Notably, a picrate anion bridge played a crucial role: as revealed by single crystal X-ray diffraction (Scheme 2C), four picrate anions linked two Goctamers through $\mathrm{H}$-bonds between anion and two inner Gquartets. The two G-octamers (from adjacent inner and outer $\mathrm{G}_{4}$ ) gave top-to-bottom stacking with ribose interdigitated between the adjacent layers. Interestingly, the two inner layers adopted bottom-to-bottom (B-B) stacking, which is more favorable than the T-T mode with the cation binding on the more "naked" convex face between the two layers. This result aroused our interest in developing a G-octamer through similar B-B stacking.

Considering the steric interaction between the C-8 substituent and ribose, we postulated that incorporation of C-8 aryl and the rigid ribose ring might provide a new system with steric hindrance between the G-quartet to force the $\mathrm{G}_{4}$ bowls to stack in a bottom-to-bottom manner, while obstructing ribose interdigitation at the top-face (Scheme 2C). To confirm this idea, compound $\mathbf{1 b}$ was designed, prepared and applied to assemble with various alkali and alkaline earth metal cations. ${ }^{1} \mathrm{H}$ NMR spectra were obtained and selected regions of the ${ }^{1} \mathrm{H}$ NMR spectra of these G-quadruplexes were compared with the Ghexadecamer from 1a as shown in Fig. 1.

As previously reported, treating $1 \mathrm{a}$ with alkali and alkaline earth metal salts $\left(\mathrm{K}^{+}, \mathrm{Ba}^{2+}, \mathrm{Sr}^{2+}\right.$ and so on) gave two sets of signals in the ${ }^{1} \mathrm{H}$ NMR spectra, corresponding to the inner and outer G-quartet. ${ }^{56}$ Conducting similar cation binding experiments with $\mathbf{1 b}$ in $\mathrm{CDCl}_{3}$ gave a single set of ${ }^{1} \mathrm{H}$ NMR signals in all cases $\left(\mathrm{M}=\mathrm{K}^{+}, \mathrm{Ba}^{2+}\right.$, and $\mathrm{Sr}^{2+} ; \mathrm{A}^{-}=$Picrate ${ }^{-}$or $\left.\mathrm{PF}_{6}{ }^{-}\right)$. Furthermore, ESI-MS demonstrated a clear doubly charged 


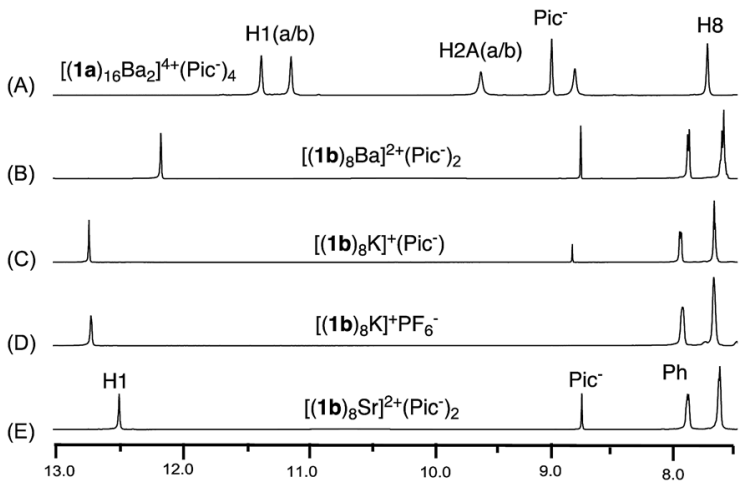

Fig. $1{ }^{1} \mathrm{H}$ NMR spectra of G-quadruplexes (A) $\left[(1 \mathrm{a})_{16} \mathrm{Ba}_{2}\right]^{4+} \cdot\left(\mathrm{Pic}^{-}\right)_{4} ;(\mathrm{B})$ $\left[(1 \mathrm{~b})_{8} \mathrm{Ba}\right]^{2+} \cdot\left(\mathrm{Pic}^{-}\right)_{2} ;(\mathrm{C})\left[(1 \mathrm{~b})_{8} \mathrm{~K}\right]^{+} \cdot\left(\mathrm{Pic}^{-}\right)_{;}(\mathrm{D})\left[(1 \mathrm{~b})_{8} \mathrm{~K}\right]^{+} \cdot\left(\mathrm{PF}_{6}{ }^{-}\right) ;(\mathrm{E})\left[(1 \mathrm{~b})_{8}{ }^{-}\right.$ $\mathrm{Sr}^{2+} \cdot\left(\mathrm{Pic}^{-}\right)_{2}$ in $\mathrm{CDCl}_{3}$

peak at $m / z=2123.01$, corresponding to a mol. wt of 4246.68 for $\left[(\mathbf{1 b})_{8} \mathrm{Ba}\right]^{2+}$. The experimental and calculated isotope patterns further suggested an octameric composition. In addition, traveling wave ion mobility-mass spectrometry (TWIM-MS) ${ }^{57}$ confirmed no formation of stacking isomers, which excluded the formation of random aggregates in gas phase (see ESI $\dagger$ for details).

Finally, single crystal structures were obtained and unambiguously verified the $\mathrm{G}_{8}$-octamer formation with the proposed bottom-to-bottom stacking (Fig. 2A). The top view of the crystal structure (Fig. 2B) shows the G-quartet self-assembly in the tail to tail orientation. The five crystal structures obtained with ligand $\mathbf{1 b}$ include monovalent cations $\left(\mathrm{K}^{+}\right.$and $\left.\mathrm{Rb}^{+}\right)$and divalent cations $\left(\mathrm{Ba}^{2+}\right.$ and $\left.\mathrm{Sr}^{2+}\right)$. Picrate anion showed no clear binding with the G-quartet, consistent with what was observed in the ${ }^{1} \mathrm{H}$ NMR spectra (see Fig. S2 $\dagger$ ). A complex with non-coordinated $\mathrm{PF}_{6}{ }^{-}$anion was also successfully obtained, $\left[(\mathbf{1 b})_{8} \mathrm{~K}\right]^{+} \cdot\left(\mathrm{PF}_{6}{ }^{-}\right)$, confirming the "anion-free" binding mode of this new type of $\mathrm{G}_{8}$-quadruplex. The distances of the $\mathrm{H}$-bond within the $\mathrm{G}_{4^{-}}$quartet and between the $\mathrm{G}_{4}$ layers are compared in Table 1 .

According to these crystal structures, all G-octamers from $\mathbf{1 b}$

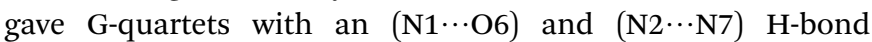
distance of around $2.9 \AA$, similar to that of the inner and outer layer in the $\mathrm{G}_{16}$-hexadecamer formed from $1 \mathbf{1 a}^{\mathbf{4 6}}$ These results indicated that both cations and the C-8 phenyl substituent had little influence on the $\mathrm{H}$-bond in the $\mathrm{G}_{4}$-quartet.

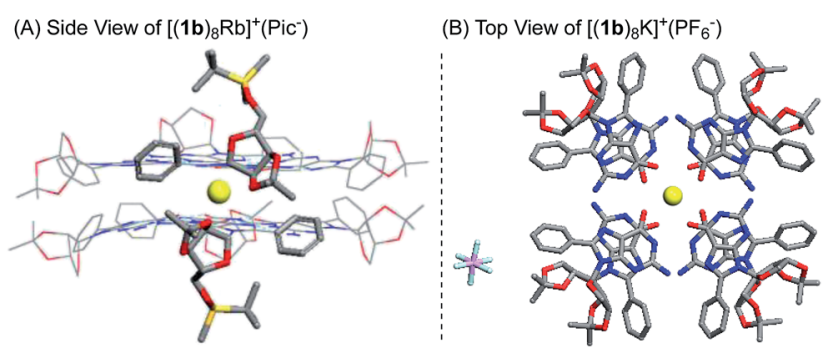

Fig. 2 X-ray single crystal structure of the $\mathrm{G}_{8}$-octamer (A) [(1b) $)_{8-}$ $\mathrm{Rb}]^{+} \cdot\left(\mathrm{Pic}^{-}\right)$; (B) $\left[(1 \mathrm{~b})_{8} \mathrm{~K}\right]^{+} \cdot\left(\mathrm{PF}_{6}{ }^{-}\right)$. Similar structures for $\left[(1 \mathrm{~b})_{8} \mathrm{~K}\right]^{+} \cdot\left(\mathrm{Pic}^{-}\right)$, $\left[(1 \mathrm{~b})_{8} \mathrm{Ba}\right]^{2+} \cdot\left(\mathrm{Pic}^{-}\right)_{2}$ and $\left[(1 \mathrm{~b})_{8} \mathrm{Sr}\right]^{2+} \cdot\left(\mathrm{Pic}^{-}\right)_{2}$ were also obtained. $\S$
However, the size of the $\mathrm{G}_{8}$ was influenced by the average $\mathrm{O}-\mathrm{M}$ distances of all these complexes from $\mathbf{1 b}$, which might follow the trend where higher ionic potential $(Z / r)$ resulted in shorter O-M distance (2.75-2.81 $\mathrm{A})$. Interestingly, in comparison with the $\mathrm{G}_{16}$-hexadecamer $\left[(\mathbf{1 a})_{16} \mathrm{Ba}_{2}\right]^{4+} \cdot\left(\mathrm{Pic}^{-}\right)_{4}$, the $\mathrm{G}_{8}$-octamers $\left[(\mathbf{1 b})_{8} \mathrm{Ba}_{2}\right]^{2+} \cdot\left(\mathrm{Pic}^{-}\right)_{2}$ gave a slightly shorter distance between the two $\mathrm{G}_{4}$ layers $(2.89 \AA$ vs. $3.06 \AA$ and $3.58 \AA$ ). This result implied the stronger cation interaction of the $(\mathbf{1 b})_{4}$-quartet than the (1a) $)_{4}$-quartet. This improved cation interaction has been supported by $\mathrm{G}_{4}$-binding studies with $\mathrm{Rb}^{+}$using the $\mathbf{1 b}$ ligand and led to the first crystal structures of $\mathrm{Rb}^{+}$coordinated G-quadruplexes. Among all the $\mathrm{G}_{8}$ crystals, $\left[(\mathbf{1 b})_{8} \mathrm{Rb}\right]^{+} \cdot\left(\mathrm{Pic}^{-}\right)$ gave the longest $\mathrm{O}-\mathrm{M}$ and $\mathrm{G}_{4}-\mathrm{G}_{4}$ distance due to its large radii $^{58}$ and low valency. Very few examples of $\mathrm{Rb}$ coordinated G-quartets have been reported so far, indicating how challenging it is for guanosine to bind with $\mathrm{Rb}$ to form a discrete $\mathrm{G}$ quadruplex. ${ }^{59}$ To the best of our knowledge, this is the first single crystal structure of a G-quadruplex containing $\mathrm{Rb}^{+}$, clearly suggesting the promising cation binding ability of guanosine derivative $\mathbf{1 b}$.

Having successfully confirmed a new concise $\mathrm{G}_{8}$-quadruplex structure in solution (NMR), solid state (XRD) and gas phase (ESI-MS and TWIM-MS), we evaluated its stability in MeOH. Dissolving octamer $\left[(\mathbf{1 b})_{8} \mathrm{~K}\right]^{+} \cdot\left(\mathrm{Pic}^{-}\right)$in $\mathrm{CD}_{3} \mathrm{OD}$ gave a mixture of two sets of signals in NMR spectra, suggesting partial decomposition of this $\mathrm{G}_{8}$-octamer (vide infra). To obtain $\mathrm{MeOH}$ stable G-quadruplexes, further modification is still needed.

\section{Cross-layer H-bonded G-octamers}

To further improve the stability of the G-quadruplex, we sought to establish the interactions between the G-quartet layers. As highlighted in Fig. 2A, the 8-phenyl group in $\mathbf{1 b}$ adopted a tilted conformation and reached out from the G-quartet. This geometry provided an opportunity to further enhance the supramolecular structure by introducing new interactions between the two G-quartets.

Notably, the Rivera group have reported the formation of an intralayer $\mathrm{H}$-bond between carbonyl oxygen with $\mathrm{N}(2) \mathrm{H}$ within the same G-quartet by using 2 -deoxy guanosine derivatives without rigid ribose functionalization. ${ }^{34,36-38}$ This work suggested the possibility of forming extra $\mathrm{H}$-bonds by using both hydrogens of the $\mathrm{N}(2)-\mathrm{NH}_{2}$ group. Inspired by this work, a carbonyl group was introduced at the meta-position of the 8aryl position of $\mathbf{1 b}$ as illustrated in Fig. 3A. Based on this design, we hypothesized that $\mathrm{N}(2)-\mathrm{H}_{\mathrm{A}}$ would form a $\mathrm{H}$-bond with neighboring guanosine within the G-quartet, while the $\mathrm{N}(2)-\mathrm{H}_{\mathrm{B}}$ could interact with the carbonyl group by forming a cross-layer H-bond.

To confirm this idea, compound 1c was synthesized and applied to G-quadruplex construction upon interacting with metal cations. According to the ${ }^{1} \mathrm{H}$ NMR spectra, treating 1c with $\mathrm{Ba}(\mathrm{Pic})_{2}$ led to the formation of a new G-quadruplex with one set of signals, similar to the $\mathrm{G}_{8}$-octamer obtained from $\mathbf{1 b}$. Analysis of the NMR sample (in $\mathrm{CDCl}_{3}$ ) by ESI-MS gave a dominant, doubly charged peak with $\mathrm{m} / \mathrm{z}$ at 2291.34, corresponding to $\left[(1 \mathrm{c})_{8} \mathrm{Ba}\right]^{2+}(\mathrm{mw}=4582.68)$. 
Table 1 G-quadruplex structural comparison (Å)

\begin{tabular}{|c|c|c|c|c|c|}
\hline G-quadruplex & & $d(\mathrm{~N} 1 \cdots \mathrm{O} 6)$ & $d(\mathrm{~N} 2 \cdots \mathrm{N} 7)$ & $d(\mathrm{O}-\mathrm{M})$ & $d\left(\mathrm{G}_{4}-\mathrm{G}_{4}\right)$ \\
\hline \multirow{2}{*}[(\mathbf{1a})_{16}\mathrm{Ba}_{2}]{$^{4+} \cdot\left(\mathrm{Pic}^{-}\right)_{4}{ }^{a}$} & Inner & $2.92 \pm 0.01$ & $2.91 \pm 0.07$ & $2.75 \pm 0.02$ & $3.06(\mathrm{i}-\mathrm{o})$ \\
\hline & Outer & $2.86 \pm 0.01$ & $2.89 \pm 0.04$ & $2.79 \pm 0.03$ & $3.58(\mathrm{i}-\mathrm{i})$ \\
\hline$\left[(\mathbf{1 b})_{8} \mathrm{~K}\right]^{+} \cdot\left(\mathrm{PF}_{6}^{-}\right)$ & & $2.82 \pm 0.04$ & $2.89 \pm 0.05$ & $2.77 \pm 0.03$ & 2.96 \\
\hline$\left[(\mathbf{1 b})_{8} \mathrm{Ba}\right]^{2+} \cdot\left(\mathrm{Pic}^{-}\right)_{2}$ & & $2.89 \pm 0.04$ & $2.89 \pm 0.04$ & $2.72 \pm 0.05$ & 2.89 \\
\hline$\left[(\mathbf{1 b})_{8} \mathrm{Sr}\right]^{2+} \cdot\left(\mathrm{Pic}^{-}\right)_{2}$ & & $2.83 \pm 0.03$ & $2.86 \pm 0.04$ & $2.62 \pm 0.05$ & 2.75 \\
\hline
\end{tabular}

${ }^{a}$ See ref. 46.

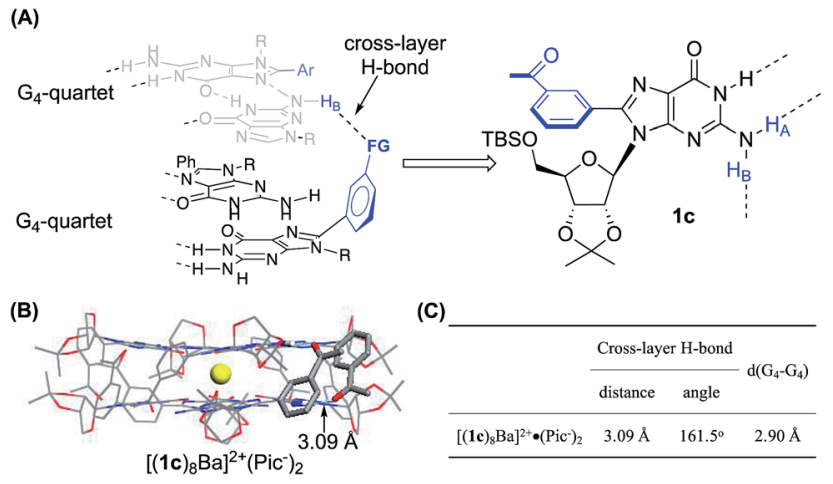

Fig. 3 (A) General design of establishing a cross-layer $\mathrm{H}$-bond; (B) single crystal structure and (C) $\mathrm{H}$-bond information of $\left[(1 \mathrm{c})_{8} \mathrm{Ba}\right]^{2+} \cdot\left(\mathrm{Pic}^{-}\right)_{2} \cdot \S$

Having confirmed the $\mathrm{G}_{8}$-octamer $\left[(\mathbf{1 b})_{8} \mathrm{Ba}\right]^{2+} \cdot\left(\mathrm{Pic}^{-}\right)_{2}$ formation, our next goal was to determine if there was a cross-layer $\mathrm{H}$ bond as designed above. The ${ }^{1} \mathrm{H}$ NMR spectra of $\left[(\mathbf{1 b})_{8^{-}}\right.$ $\mathrm{Ba}]^{2+} \cdot\left(\mathrm{Pic}^{-}\right)_{2}$ and $\left[(\mathbf{1 c})_{8} \mathrm{Ba}\right]^{2+} \cdot\left(\mathrm{Pic}^{-}\right)_{2}$ did not show peaks corresponding to $\mathrm{N}(2) \mathrm{H}$ at room temperature. This is likely due to the rapid exchange between the two $\mathrm{NH}_{2}$ protons, even with the formation of a H-bond. Thus, the exchange rate of the two protons provides a direct indication of the $\mathrm{H}$-bond strength in the $\mathrm{G}_{4}$-quartet. To explore the dynamic structure, variable temperature (VT) NMR experiments with $\left[(\mathbf{1 b})_{8} \mathrm{Ba}\right]^{2+} \cdot\left(\mathrm{Pic}^{-}\right)_{2}$ and $\left[(\mathbf{1 c})_{8^{-}}\right.$ $\mathrm{Ba}]^{2+} \cdot\left(\mathrm{Pic}^{-}\right)_{2}$ were performed and are summarized in Fig. 4.

For complex $\left[(\mathbf{1 c})_{8} \mathrm{Ba}\right]^{2+} \cdot\left(\mathrm{Pic}^{-}\right)_{2}$, the $\mathrm{NH}_{2}$ protons started appearing as broad peaks at $0{ }^{\circ} \mathrm{C}$ with the chemical shift at $10.28 \mathrm{ppm}\left(\mathrm{H}_{\mathrm{A}}\right)$ and $7.25 \mathrm{ppm}\left(\mathrm{H}_{\mathrm{B}}\right)$. In contrast, the VT NMR
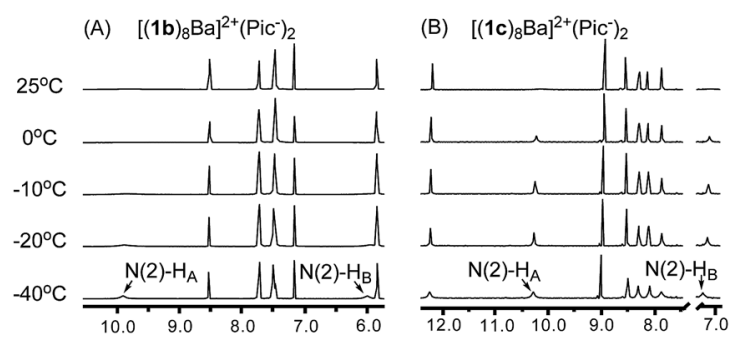

Fig. 4 (A) VT NMR spectra of $\left[(1 \mathrm{~b})_{8} \mathrm{Ba}\right]^{2+} \cdot\left(\mathrm{Pic}^{-}\right)_{2}$ and (B) VT NMR spectra of $\left[(1 \mathrm{C})_{8} \mathrm{Ba}\right]^{2+} \cdot\left(\mathrm{Pic}^{-}\right)_{2}$ confirmed the cross-layer $\mathrm{H}$-bond design in establishing a cross-layer $\mathrm{H}$-bond. spectra of $\left[(\mathbf{1 b})_{8} \mathrm{Ba}\right]^{2+} \cdot\left(\mathrm{Pic}^{-}\right)_{2}$ did not show apparent peaks of the $\mathrm{N}(2)-\mathrm{H}$ signals until further cooling the sample to $-40{ }^{\circ} \mathrm{C}$. The results indicated that there might be an extra $\mathrm{H}$-bond in the 1c complex to lock the $\mathrm{N}(2)-\mathrm{NH}_{2}$ from rapid exchange. Furthermore, a significantly downfield shifted chemical shift (7.25 $\mathrm{ppm}$ ) was ascribed to the $\mathrm{N}(2)-\mathrm{H}_{\mathrm{B}}$ proton in the $(\mathbf{1 c})_{8}$-octamer compared with the $(\mathbf{1 b})_{8}$-octamer $(5.98 \mathrm{ppm})$. These observations provide clear evidence of the formation of a cross-layer $\mathrm{H}$ bond in the $(\mathbf{1 c})_{8}$-octamer as designed.

Finally, the $\mathrm{G}_{8}$-octamer was verified by X-ray crystallography as shown in Fig. 3B. The crystal structure also confirmed the presence of the cross-layer interactions with a mean $\mathrm{H}$-bond distance of $3.09 \AA$ and a bond angle of $161.5^{\circ}$, suggesting a weak cross-layer $\mathrm{H}$-bond present in solid state (Fig. 3C). This makes the structure a "self-assembled molecular-cuboid" purely constructed by $\mathrm{H}$-bond linkage with all eight guanosine units. On the other hand, the distance of the two G-quartet layers $\left(\begin{array}{ll}2.90 \AA & \AA\end{array}\right)$ in $\left[(\mathbf{1 c})_{8} \mathrm{Ba}\right]^{2+} \cdot\left(\mathrm{Pic}^{-}\right)_{2}$ remained similar to the $\mathbf{1 b}$ complex. Considering the specific "cage" size in the $\mathrm{G}_{8}$-octamer shown in Table 1, the cross-layer H-bond was not strong enough to generate extra enthalpy gain to balance the entropy cost caused by holding the two layers tighter.

With the confirmed cross-layer H-bonds, we evaluated the complex stability of $\left[(\mathbf{1 c})_{8} \mathrm{~K}\right]^{+} \cdot\left(\mathrm{Pic}^{-}\right)$in methanol. The results showed a similar stability to the complex formed with $\mathbf{1 b}$ (vide infra). Although the cross-layer $\mathrm{H}$-bond approach could not boost $\mathrm{G}_{8}$-quadruplex stability in $\mathrm{MeOH}$ as anticipated, it provided an effective and novel approach to enhance Gquadruplex stability from monomer conformational design. Structural amendment was required to further improve the stability of the $\mathrm{G}_{8}$-octamer.

\section{Cross-layer linkage through a covalent bond}

To increase the stability to a new level, we turned to establishing a potential covalent linkage between the two G-quartets. By scrutinizing the crystal structure of $\left[(\mathbf{1 b})_{8} \mathrm{Ba}\right]^{2+} \cdot\left(\mathrm{Pic}^{-}\right)_{2}$, we found that the distance between the two meta position of the phenyl ring from each tetramer was $4.0 \AA$, a distance similar to three single bond lengths. ${ }^{58}$ According to the observation, the meta position of the two phenyl groups could serve as a reference site for constructing cross-layer covalent linkers. The guanosine dimer $\mathbf{1 d}$ and $\mathbf{1} \mathbf{d}^{\prime}$ were then prepared using the synthetic route summarized in Fig. 5A. 
(A) Synthesis of bis-guanosine through covalent linkage

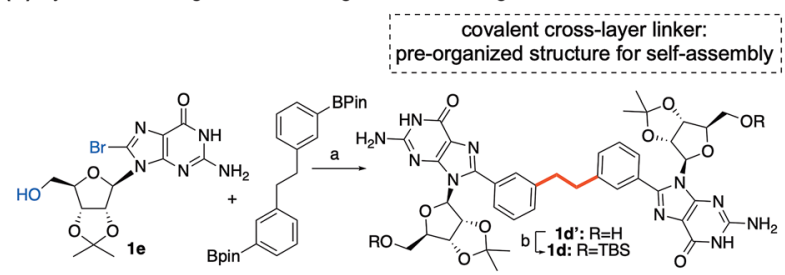

(a) $10 \% \mathrm{Pd}\left(\mathrm{PPh}_{3}\right)_{4}, \mathrm{Na}_{2} \mathrm{CO}_{3}$ (2.0 equiv.) $\mathrm{CH}_{3} \mathrm{CN}: \mathrm{H}_{2} \mathrm{O}=5: 1,110^{\circ} \mathrm{C}, 80 \%$; b) TBDMSCI (4.0 equiv.), imidazole (4.0 equiv.), $\mathrm{CH}_{2} \mathrm{Cl}_{2}, \mathrm{rt}, 60 \%$.

(B) Single crystal of $\left[\left(\mathbf{1 d}^{\prime}\right)_{4} \mathrm{~K}\right]^{+} \mathrm{Pic}^{-}$grown from DMSO co-solvents

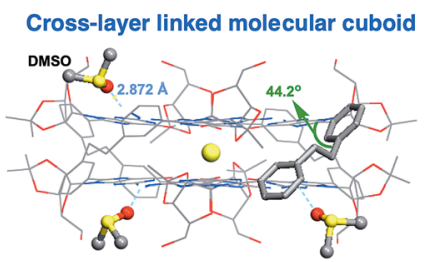

Side View

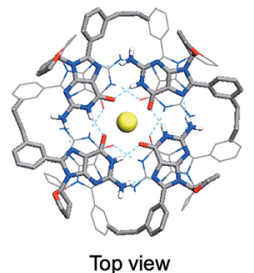

Fig. 5 (A) Synthesis of bis-guanosine derivatives. (B) Single crystal structure of $\left[\left(1 d^{\prime}\right) 4 \mathrm{~K}\right]^{+} \cdot\left(\mathrm{Pic}^{-}\right) . \S$

Self-assembly of $\mathbf{1 d}$ with $\mathrm{K}^{+}$and $\mathrm{Ba}^{2+}$ cations in $\mathrm{CDCl}_{3}$ gave a similar one-set of signals in the ${ }^{1} \mathrm{H}$ NMR spectra, consistent with the formation of $\mathrm{G} \mathrm{G}_{8}$-octamer. ESI-MS of complexes from 1d and $\mathrm{Ba}^{2+}$ gave a doubly charged peak at $m / z=2175.55$ as the dominant signal, indicating a mol. wt of 4351.1 for the supermolecule as $\left[(\mathbf{1 d})_{4} \mathrm{Ba}\right]^{2+}$. An attempt to obtain a single crystal of the 1d complex failed initially, resulting in a rather thin, filmlike solid formation. Fortunately, the single crystal structure was successfully obtained by switching the monomer to $\mathbf{1 d}^{\prime}$ using DMSO as a co-solvent, confirming the cross-layer covalent linked structure as proposed (Fig. 5B). Notably, for complex $\left[\left(\mathbf{1 d}^{\prime}\right)_{4} \mathrm{Ba}\right]^{2+} \cdot\left(\mathrm{Pic}^{-}\right)_{2}$, the dihedral angle between 8 -aryl and guanine is 40.7 degrees, similar to the dihedral angles in complex $\left[(\mathbf{1 b})_{8} \mathrm{Ba}\right]^{2+} \cdot\left(\mathrm{Pic}^{-}\right)_{2}$ (42.5 degrees). Overall, through Gmonomer conformational analysis, a series of $\mathrm{G}_{8}$-octamers was successfully prepared with functionalization at 8-phenyl (1b), a cross-layer H-bond linker (1c) and a covalent linker (1d).

\section{G-quadruplex H-bond stability in $\mathrm{MeOH}$}

As discussed above, our intrinsic motivation in exploring these different G-quadruplexes was to develop H-bonded guanosine self-assembly that could survive in protic solvents (H-bond competitive). With all these different $\mathrm{G}_{16}$ and $\mathrm{G}_{8}$ quadruplexes prepared, we dissolved them in $\mathrm{CD}_{3} \mathrm{OD}$ to compare the ${ }^{1} \mathrm{H}$ NMR spectra. As shown in Fig. 6A, N(1)-H and $\mathrm{N}(2)-\mathrm{H}$ protons did not appear in ${ }^{1} \mathrm{H}$ NMR spectra with $\mathrm{CD}_{3} \mathrm{OD}$ as the solvent due to the $\mathrm{H} / \mathrm{D}$ exchange. Thus, evaluation of the ${ }^{1} \mathrm{H}$ NMR spectra will mainly be focused on the non-exchangeable aromatic protons and ribose protons. Dissolving the $\mathrm{G}_{16}$-hexadecamer $\left[(\mathbf{1 a})_{16^{-}}\right.$ $\left.\mathrm{K}_{4}\right]^{4+} \cdot\left(\mathrm{Pic}^{-}\right)_{4}$ in $\mathrm{CD}_{3} \mathrm{OD}$ gave only one set of signals, identical to the 1a monomer in $\mathrm{CD}_{3} \mathrm{OD}$. The result suggested complete dissociation of the $\mathrm{G}_{16}$-hexadecamer to 1 a monomer in $\mathrm{MeOH}$. Interestingly, the $\mathrm{G}_{8}$-octamer $\left[(\mathbf{1 b})_{8} \mathrm{~K}\right]^{+} \cdot\left(\mathrm{Pic}^{-}\right)$and $\left[(\mathbf{1 c})_{8^{-}}\right.$ $\mathrm{K}]^{+} \cdot\left(\mathrm{Pic}^{-}\right)$in $\mathrm{CD}_{3} \mathrm{OD}$ gave two sets of signals, indicating the existence of dissociated monomer and possible oligomers or

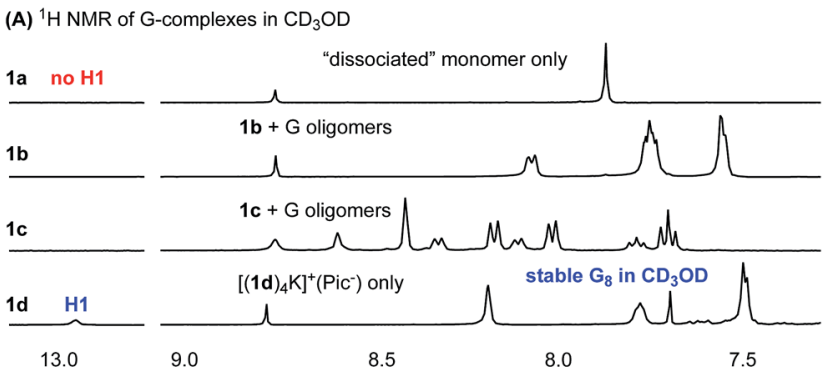

(B)

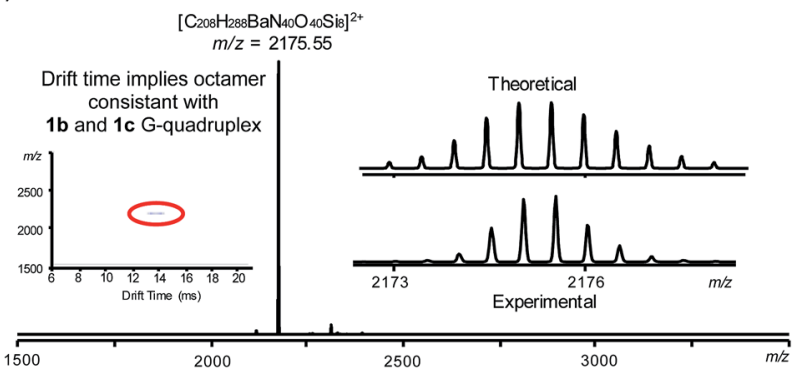

Fig. 6 (A) ${ }^{1} \mathrm{H}$ NMR spectra showing $\mathrm{G}$-quadruplex stability in $\mathrm{CD}_{3} \mathrm{OD}$. (B) $\mathrm{MS}$ of $\left[(1 \mathrm{~d})_{4} \mathrm{Ba}\right]^{2+} \cdot\left(\mathrm{Pic}^{-}\right)_{2}$ in $\mathrm{MeOH}$.

a G-quadruplex in the solution phase. Although the exact structures of the guanosine species in these two cases are not determined at this moment, the fact that $\mathrm{H}$-bonded guanosine complexes were formed with $\mathbf{1 b}$ and $\mathbf{1 c}$ clearly suggests the improved H-binding ability of these two monomers over 1a. Surprisingly, when dissolving the $\mathrm{G}_{8}$-octamer $\left[(\mathbf{1 d})_{4} \mathrm{~K}\right]^{+} \cdot\left(\mathrm{Pic}^{-}\right)$in $\mathrm{CD}_{3} \mathrm{OD}$, only one set of signals was observed. Notably, in this case, $\mathrm{N}(1)-\mathrm{H}$ gave a broad signal at $12.95 \mathrm{ppm}$, clearly suggesting the formation of a G-quadruplex through a H-bond. NMR solvent signal suppression was applied for the G-quadruplex $\left[(\mathbf{1 d})_{4^{-}}\right.$ $\mathrm{K}]^{+} \cdot\left(\mathrm{Pic}^{-}\right)$in $\mathrm{CD}_{3} \mathrm{OH}$. The peak at $12.9 \mathrm{ppm}$ clearly showed up and was confirmed to be $\mathrm{H} 1$ of $\mathrm{G}$ in the G-quadruplex (see detailed NMR spectra in Fig. S7†). Thus, with monomer 1d, a Gquadruplex remains intact in protic solvent $\mathrm{CD}_{3} \mathrm{OD}$. Impressively, this G-quadruplex did not dissociate even at elevated temperature in $\mathrm{CD}_{3} \mathrm{OD}$, with the $\mathrm{N}(1) \mathrm{H}$ peak remaining at $60{ }^{\circ} \mathrm{C}$ (see Fig. $\mathrm{S} 6 \dagger$ for VT NMR spectra). This observation indicated that there was a high kinetic barrier to break the 1d G-quartet for H/D exchange, which highlighted the stability of $\left[(\mathbf{1 d})_{4} \mathrm{~K}\right]^{+} \cdot\left(\mathrm{Pic}^{-}\right)$in a $\mathrm{H}$-bond competitive system. Injecting an $\mathrm{MeOH}$ solution of $\left[(\mathbf{1 d})_{4^{-}}\right.$ $\mathrm{Ba}]^{2+} \cdot\left(\mathrm{Pic}^{-}\right)_{2}$ complex into ESI-MS gave a dominant double charged peak with $\mathrm{m} / z=2175.55$, corresponding to $\left[(\mathbf{1 d})_{4} \mathrm{Ba}\right]^{2+}$ (Fig. 6B). It is noteworthy that TWIM-MS of this G-quadruplex in methanol solution was recorded as a single band $(\mathrm{m} / \mathrm{z}=2175.55)$ with drift time at $14.33 \mathrm{~ms}$, which is in agreement with the size of the $\mathrm{G}_{8}$-octamer (see detailed discussion in Table $\mathrm{S} 1 \dagger$ ). To the best of our knowledge, this is one of the few stable G-quadruplex systems from small molecule self-assembly to survive in a $\mathrm{H}$ bond competitive environment.

\section{Evaluating G-quadruplex stability}

With the success in maintaining G-quadruplex stability in protic solvent $\mathrm{MeOH}$, we sought to evaluate whether a similar 
stability trend exists with polar aprotic solvents. DMSO is a strong polar solvent, which can disrupt the H-bond in Gquartets and cause the decomposition of G-quadruplexes. To evaluate how the incorporation of the phenyl group and crosslayer interaction impact on thermodynamic stability, Gquadruplexes were treated with $\mathrm{CDCl}_{3} / \mathrm{DMSO} \mathrm{d}_{6}$ solvent mixture. A summary of ${ }^{1} \mathrm{H}$ NMR spectra from these experiments is shown in Fig. 7.

As shown in the ${ }^{1} \mathrm{H}$ NMR spectra, G-quadruplexes from 1a, $\mathbf{1 b}$ and $\mathbf{1 c}$ started to dissociate in mixed solvents containing $20 \%$ DMSO- $_{6}$. Compared with the reported $\mathrm{G}_{16}$-hexadecamer from $\mathbf{1 a},{ }^{46}$ the $\mathrm{G}_{8}$-octamer formed by $\mathbf{1 b}$ and $\mathbf{1 c}$ showed comparable stability in $20 \%$ DMSO- $_{6}$. Eventually, all three Gquadruplexes gave complete dissociation in $50 \%$ DMSO- $_{6}$ solution with only one set of signals corresponding to the monomer. In contrast, $\left[(\mathbf{1 d})_{4} \mathrm{~K}\right]^{+} \cdot\left(\mathrm{Pic}^{-}\right)$showed significantly improved stability, with only $2 \%$ complex dissociation in $50 \%$ DMSO- $\mathrm{d}_{6}$. This result demonstrates the significantly enhanced stability of G-quadruplexes constructed by $\mathbf{1 d}$.

To quantify the thermodynamic stability of G-quadruplexes, ${ }^{47}$ VT NMR experiments were carried out for pure complexes of $\left[(\mathbf{1 a})_{16} \mathrm{~K}_{4}\right]^{4+} \cdot\left(\mathrm{Pic}^{-}\right)_{4},\left[(\mathbf{1 b})_{8} \mathrm{~K}\right]^{+} \cdot\left(\mathrm{Pic}^{-}\right),\left[(\mathbf{1 c})_{8} \mathrm{~K}\right]^{+} \cdot\left(\mathrm{Pic}^{-}\right)$, and $\left[(\mathbf{1 d})_{4^{-}}\right.$ $\mathrm{K}]^{+} \cdot\left(\mathrm{Pic}^{-}\right)$in $\mathrm{CDCl}_{3} /$ DMSO-d $_{6}$ with a fraction of $20 \%$ DMSO-d $\mathrm{d}_{6}$. The values of complex dissociation enthalpy and entropy for each G-quadruplex were calculated from van't Hoff plots and are compared in Table S6 (see detailed discussion in the ESI $\dagger$ ). For complex $\left[(\mathbf{1 d})_{4} \mathrm{~K}\right]^{+} \cdot\left(\mathrm{Pic}^{-}\right)$, no significant increase in monomer concentration was observed with the increase in temperature. This might be attributed to the high kinetic barrier for Gquadruplex $\left[(\mathbf{1 d})_{4} \mathrm{~K}\right]^{+} \cdot\left(\mathrm{Pic}^{-}\right)$dissociation. To confirm this hypothesis, a NOESY experiment at $50{ }^{\circ} \mathrm{C}$ was performed for $\left[(\mathbf{1 b})_{8} \mathrm{~K}\right]^{+} \cdot\left(\mathrm{Pic}^{-}\right),\left[(\mathbf{1 c})_{8} \mathrm{~K}\right]^{+} \cdot\left(\mathrm{Pic}^{-}\right)$and $\left[(1 \mathrm{~d})_{4} \mathrm{~K}\right]^{+} \cdot\left(\mathrm{Pic}^{-}\right)$(Fig. S14$\left.\mathrm{S} 16^{\dagger}\right)$. The results suggested that kinetic exchange between the complex and monomer for $\left[(\mathbf{1 d})_{4} \mathrm{~K}\right]^{+} \cdot\left(\mathrm{Pic}^{-}\right)$was too slow to be recorded by NMR spectroscopy.

In addition to DMSO titration, the stability of $G_{8}$ and $G_{16}$ complexes could also be evaluated using tandem-MS by

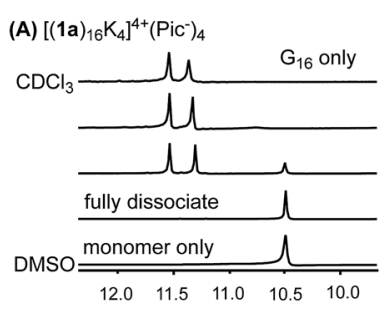

(C) $\left[(1 \mathrm{c})_{8} \mathrm{~K}\right]^{+}\left(\mathrm{Pic}^{-}\right)$
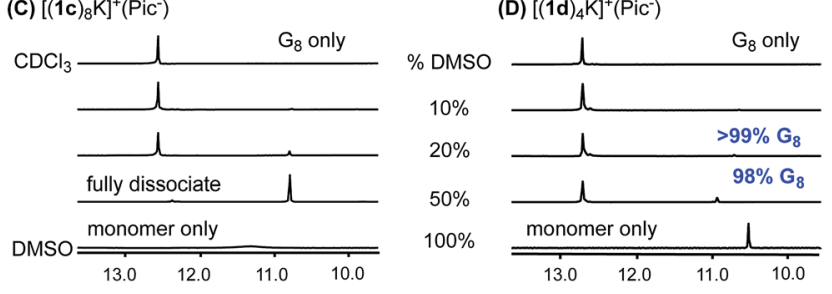

Fig. 7 DMSO- $\mathrm{d}_{6}$ titration: ${ }^{1} \mathrm{H}$ NMR spectra of $(\mathrm{A})\left[(1 \mathrm{a})_{16} \mathrm{~K}_{4}\right]^{4+}$. $\left(\mathrm{Pic}^{-}\right)_{4}$, (B) $\left[(1 \mathrm{~b})_{8} \mathrm{~K}\right]^{+} \cdot\left(\mathrm{Pic}^{-}\right),(\mathrm{C})\left[(1 \mathrm{c})_{8} \mathrm{~K}\right]^{+} \cdot\left(\mathrm{Pic}^{-}\right),(\mathrm{D})\left[(1 \mathrm{~d})_{4} \mathrm{~K}^{+} \cdot\left(\mathrm{Pic}^{-}\right)\right.$in $\mathrm{CDCl}_{3}-$ : DMSO- $d_{6}$ with DMSO- $d_{6}$ fractions of $10 \%, 20 \%$ and $50 \%$.
Table 2 Decomposition voltage

\begin{tabular}{lllll}
\hline & {$\left[(\mathbf{1 a})_{8} \mathrm{Ba}\right]^{2+}$} & {$\left[(\mathbf{1 b})_{8} \mathrm{Ba}\right]^{2+}$} & {$\left[(\mathbf{1 c})_{8} \mathrm{Ba}\right]^{2+}$} & {$\left[(\mathbf{1 d})_{4} \mathrm{Ba}\right]^{2+}$} \\
\hline Start $^{a}$ & $30 \mathrm{~V}$ & $40 \mathrm{~V}$ & $50 \mathrm{~V}$ & $70 \mathrm{~V}$ \\
End $^{a}$ & $40 \mathrm{~V}$ & $45 \mathrm{~V}$ & $65 \mathrm{~V}$ & $80 \mathrm{~V}$ \\
\multicolumn{2}{l}{${ }^{a}$ Operating voltage (V). } & & &
\end{tabular}

increasing the operating voltage. The cation fragments of Gquadruplexes were separated and treated with increasing voltage. The operating voltage for G-quadruplex cation fragment decomposition are summarized in Table 2 .

It is noteworthy that $\left[(\mathbf{1 a})_{16} \mathrm{Ba}_{2}\right]^{4+} \cdot\left(\mathrm{Pic}^{-}\right)_{4}$ only showed a doubly charged peak at $\mathrm{m} / z=2123.31$ corresponding to $\left[(1 \mathrm{a})_{8} \mathrm{Ba}\right]^{2+}$, indicating that the picrate bridge dissociated under the MS conditions. Further comparison of all the cation fragments of the G-quadruplexes revealed a clear stability trend as $\left[(\mathbf{1 d})_{4} \mathrm{Ba}\right]^{2+}>\left[(\mathbf{1 c})_{8} \mathrm{Ba}\right]^{2+}>\left[(\mathbf{1 b})_{8} \mathrm{Ba}\right]^{2+}>\left[(\mathbf{1 a})_{8} \mathrm{Ba}\right]^{2+}$. Overall, the covalent linking strategy significantly helped to stabilize the $\mathrm{G}_{8}{ }^{-}$ octamer, both in $\mathrm{H}$-bond competitive solvents and gas phase.

\section{Conclusions}

In summary, with modification on both guanine (8-aryl) and ribose (sterically hindered $2^{\prime}, 3^{\prime}$ position), a stable $\mathrm{G}_{8}$-octamer was formed with its structure characterized by single crystal Xray diffraction for the first time. Through the analysis of crosslayer interactions, a covalently tethered 8-aryl guanosine dimer was designed and prepared for supramolecular assembly. The expected $\mathrm{G}_{8}$-octamer was confirmed by X-ray, MS and NMR spectroscopy with significantly improved stability in $\mathrm{MeOH}$ and $1: 1 \mathrm{DMSO} / \mathrm{CDCl}_{3}$ mixture. To the best of our knowledge, this is the first example of discrete G-quadruplexes formed from small molecules with enhanced stability in a protic solvent $(\mathrm{MeOH})$ and a polar aprotic solvent (DMSO). Meanwhile, formation of the stable $\mathrm{G}_{8}$-octamer with a concise and well-defined bottomto-bottom stacking mode provides a novel supramolecular platform. Incorporation of this new system into material and biological applications is expected and currently undergoing in our group.

\section{Conflicts of interest}

There are no conflicts to declare.

\section{Acknowledgements}

We are grateful to the NSF (CHE-1665122), the NIH (1R01GM120240-01), and NSFC (21629201) for financial support.

\section{Notes and references}

$\S$ All the structures reported in this article have been deposited with the Cambridge Crystallographic Data Centre. The accession numbers for $\left[(\mathbf{1 b})_{8^{-}}\right.$ $\mathrm{Ba}^{2+} \cdot\left(\mathrm{Pic}^{-}\right)_{2} ; \quad\left[(\mathbf{1 b})_{8} \mathrm{~K}\right]^{+} \cdot\left(\mathrm{PF}_{6}{ }^{-}\right) ; \quad\left[(\mathbf{1 b})_{8} \mathrm{~K}\right]^{+} \cdot\left(\mathrm{Pic}^{-}\right) ; \quad\left[(\mathbf{1 b})_{8} \mathrm{Sr}^{2+} \cdot\left(\mathrm{Pic}^{-}\right)_{2}\right.$; $\left[(\mathbf{1 b})_{8} \mathrm{Rb}\right]^{+} \cdot\left(\mathrm{Pic}^{-}\right) ;\left[(\mathbf{1 c})_{8} \mathrm{Ba}\right]^{2+} \cdot\left(\mathrm{Pic}^{-}\right)_{2} ;\left[\left(\mathbf{1 d}^{\prime}\right)_{4} \mathrm{~K}\right]^{+} \cdot\left(\mathrm{Pic}^{-}\right)$reported in this paper are: 
1871565, 1871566, 1871567, 1871568, 1871569, 1871570, 1871754 correspondingly.

1 M. Fujita, Structure and Bonding, Springer, Berlin, 2000, pp. 177-201.

2 D. S. Lawrence, T. Jiang and M. Levett, Chem. Rev., 1995, 95, 2229-2260.

3 D. P. Craig and D. P. Mellor, Structure and Bonding, Springer, Berlin, 1976, pp. 1-48.

4 M. Fujita, Chem. Soc. Rev., 1998, 27, 417-425.

5 L. J. Prins, D. N. Reinhoudt and P. Timmerman, Angew. Chem., Int. Ed., 2001, 40, 2382-2426.

6 P. Y. W. Dankers and E. W. Meijer, Bull. Chem. Soc. Jpn., 2007, 80, 2047-2073.

7 H.-W. Jun, S. E. Paramonov and J. D. Hartgerink, Soft Matter, 2006, 2, 177-181.

8 P. Xin, P. Zhu, P. Su, J.-L. Hou and Z.-T. Li, J. Am. Chem. Soc., 2014, 136, 13078-13081.

9 J. T. Davis, Angew. Chem., Int. Ed., 2004, 43, 668-698.

10 J. L. Sessler, C. M. Lawrence and J. Jayawickramarajah, Chem. Soc. Rev., 2007, 36, 314-325.

11 C. L. D. Gibb and B. C. Gibb, J. Am. Chem. Soc., 2004, 126, 11408-11409.

12 G. V. Oshovsky, D. N. Reinhoudt and W. Verboom, Angew. Chem., Int. Ed., 2007, 46, 2366-2393.

13 J. T. Davis and G. P. Spada, Chem. Soc. Rev., 2007, 36, 296313.

14 G. P. Spada and G. Gottarelli, Synlett, 2004, 4, 596-602.

15 E. Bouhoutsos-Brown, C. L. Marshall and T. J. Pinnavaia, J. Am. Chem. Soc., 1982, 104, 6576-6584.

16 J. P. N. V. Hud, Quadruplex Nucleic Acids, The Royal Society of Chemistry, Cambridge, 2006, pp. 100-130.

17 J. A. Walmsley, R. G. Barr, E. Bouhoutsos-Brown and T. J. Pinnavaia, J. Phys. Chem., 1984, 88, 2599-2605.

18 G. Biffi, M. Di Antonio, D. Tannahill and S. Balasubramanian, Nat. Chem., 2013, 6, 75.

19 J. N. Parkinson, Quadruplex Nucleic Acids, The Royal Society of Chemistry, Cambridge, 2006, pp. 1-30.

20 M. Zeraati, D. B. Langley, P. Schofield, A. L. Moye, R. Rouet, W. E. Hughes, T. M. Bryan, M. E. Dinger and D. Christ, Nat. Chem., 2018, 10, 631-637.

21 I. C. M. Kwan, Y.-M. She and G. Wu, Can. J. Chem., 2011, 89, 835-844.

22 M. a. D. C. Rivera-Sánchez, M. García-Arriaga, G. Hobley, A. V. Morales-de-Echegaray and J. M. Rivera, ACS Omega, 2017, 2, 6619-6627.

23 M. d. C. Rivera-Sánchez, I. Andújar-de-Sanctis, M. GarcíaArriaga, V. Gubala, G. Hobley and J. M. Rivera, J. Am. Chem. Soc., 2009, 131, 10403-10405.

24 R. N. Das, Y. P. Kumar, O. M. Schütte, C. Steinem and J. Dash, J. Am. Chem. Soc., 2015, 137, 34-37.

25 S. L. Forman, J. C. Fettinger, S. Pieraccini, G. Gottarelli and J. T. Davis, J. Am. Chem. Soc., 2000, 122, 4060-4067.

26 M. S. Kaucher, W. A. Harrell and J. T. Davis, J. Am. Chem. Soc., 2006, 128, 38-39.

27 T. Bhattacharyya, P. Saha and J. Dash, ACS Omega, 2018, 3, 2230-2241.
28 G. M. Peters and J. T. Davis, Chem. Soc. Rev., 2016, 45, 31883206.

29 G. M. Peters, L. P. Skala and J. T. Davis, J. Am. Chem. Soc., 2016, 138, 134-139.

30 M. García-Iglesias, T. Torres and D. González-Rodríguez, Chem. Commun., 2016, 52, 9446-9449.

31 D. González-Rodríguez, P. G. A. Janssen, R. Martín-Rapún, I. D. De Cat, S. De Feyter, A. P. H. J. Schenning and E. W. Meijer, J. Am. Chem. Soc., 2010, 132, 4710-4719.

32 H. Han and L. H. Hurley, Trends Pharmacol. Sci., 2000, 21, 136-142.

33 F. W. B. Van Leeuwen, W. Verboom, X. Shi, J. T. Davis and D. N. Reinhoudt, J. Am. Chem. Soc., 2004, 126, 16575-16581.

34 J. E. Betancourt, C. Subramani, J. L. Serrano-Velez, E. RosaMolinar, V. M. Rotello and J. M. Rivera, Chem. Commun., 2010, 46, 8537-8539.

35 S. Martic, G. Wu and S. Wang, Inorg. Chem., 2008, 47, 83158323.

36 J. M. Rivera, M. Martín-Hidalgo and J. C. Rivera-Ríos, Org. Biomol. Chem., 2012, 10, 7562-7565.

37 J. M. Rivera and D. Silva-Brenes, Org. Lett., 2013, 15, 23502353.

38 M. Martín-Hidalgo and J. M. Rivera, Chem. Commun., 2011, 47, 12485-12487.

39 K. B. Sutyak, P. Y. Zavalij, M. L. Robinson and J. T. Davis, Chem. Commun., 2016, 52, 11112-11115.

40 J. E. Betancourt, M. Martín-Hidalgo, V. Gubala and J. M. Rivera, J. Am. Chem. Soc., 2009, 131, 3186-3188.

41 D. González-Rodríguez, J. L. J. van Dongen, M. Lutz, A. L. Spek, A. P. H. J. Schenning and E. W. Meijer, Nat. Chem., 2009, 1, 151-155.

42 J. E. Betancourt and J. M. Rivera, J. Am. Chem. Soc., 2009, 131, 16666-16668.

43 J. E. Betancourt and J. M. Rivera, Org. Lett., 2008, 10, 22872290.

44 V. Gubala, J. E. Betancourt and J. M. Rivera, Org. Lett., 2004, 6, 4735-4738.

45 S. B. Zimmerman, J. Mol. Biol., 1976, 106, 663-672.

46 X. Shi, K. M. Mullaugh, J. C. Fettinger, Y. Jiang, S. A. Hofstadler and J. T. Davis, J. Am. Chem. Soc., 2003, 125, 10830-10841.

47 E. Fadaei, M. Martín-Arroyo, M. Tafazzoli and D. GonzálezRodríguez, Org. Lett., 2017, 19, 460-463.

48 M. García-Arriaga, G. Hobley and J. M. Rivera, J. Am. Chem. Soc., 2008, 130, 10492-10493.

49 A. L. Marlow, E. Mezzina, G. P. Spada, S. Masiero, J. T. Davis and G. Gottarelli, J. Org. Chem., 1999, 64, 5116-5123.

50 M. García-Arriaga, G. Hobley and J. M. Rivera, J. Org. Chem., 2016, 81, 6026-6035.

51 S. Lena, P. Neviani, S. Masiero, S. Pieraccini and G. P. Spada, Angew. Chem., Int. Ed., 2010, 49, 3657-3660.

52 S. Marti, X. Liu, S. Wang and G. Wu, Chem.-Eur. J., 2008, 14, 1196-1204.

53 X. Meng, T. Moriuchi, M. Kawahata, K. Yamaguchi and T. Hirao, Chem. Commun., 2011, 47, 4682-4864.

54 J. L. Sessler, M. Sathiosatham, K. Doerr, V. Lynch and K. A. Abboud, Angew. Chem., Int. Ed., 2000, 39, 1300-1303. 
55 X. Shi, J. C. Fettinger and J. T. Davis, Angew. Chem., Int. Ed., 2001, 40, 2827-2831.

56 X. Shi, J. C. Fettinger and J. T. Davis, J. Am. Chem. Soc., 2001, 123, 6738-6739.

57 H. Wang, X. Qian, K. Wang, M. Su, W.-W. Haoyang, X. Jiang, R. Brzozowski, M. Wang, X. Gao, Y. Li, B. Xu, P. Eswara,
X.-Q. Hao, W. Gong, J.-L. Hou, J. Cai and X. Li, Nat. Commun., 2018, 9, 1815.

58 J. G. Speight, Lange's Handbook of Chemistry, McGraw-Hill, New York, 16th edn, 2005, pp. 1-150.

59 R. Ida and G. Wu, Chem. Commun., 2005, 4294-4296. 